\title{
ПСИХОИСТОРИЧЕСКИЙ ДИСКУРС УКРАИНСКОЙ ИСТОРИИ
}

В данной статье автор на основании общеизвестной схемы периодизации украинской истории выделяет элементы психоисторического дискурса, предлагая свою версию их взаимосвязи и согласованности.

Психоистория как метод и самостоятельная научная дисциплина существует уже более сорока лет, но в украинской историографии она не обрела качественного воплощения, хотя именно она иллюстрирует собой современный формат человеческого измерения истории.

Автор рассматривает психоисторический дискурс таких явлений и периодов в украинской истории как украинское казачество и проблема гетманского лидерства, столыпинская аграрная реформа, украинская национальная революция в проекции личности М.Грушевского, Великая отечественная и вторая мировая война, психоисторические портреты некоторых политических персонажей современного периода.

Главные выводы, к которым приходит автор: казачество является отдельным психокласом в современном ему украинском обществе и психоистория украинского казачества может быть репрезентована в качестве групповой фантазии как результат исторической мотивации в протистоянии враждебным иноземным вторжениям; Б.Хмельницкий имел определённые проблемы с получением прав на руководство государством, поскольку по происхождению был всего лишь мелким шляхтичем, он и другие украинские гетманы для законного осуществления собственных амбиций в процессе создания государства должны были либо получить княжеские титулы в соответствии с существующими процедурами, либо же предложить иную альтернативную модель.

Обозначен конфликт между традиционной властью и реформаторами - Сергеем Юльевичем Витте и Петром Аркадиевичем Столыпиным, где главным действующим лицом становится император Николай II. Отношение царя к названным министрам характеризуется состоянием раздражения, которое блокирует рациональное понимание Николаем II необходимости коренных изменений в империи.

Что же касаемо периода войн. Последствия военного опыта, если не были психологически обработаны проявляют себя в огрубении, в невозможности к сложной форме взаимодействий с другими людьми, в вытеснении более сложных представлений о мире.

Украинские политики, как и какие-либо другие, реализуют детскую систему родственных отношений. То есть в зависимости от биографии они окружают себя символическими родителями, братьями и сёстрами, как в виде людей, так и институций. Говоря о реальних политиках последнего десятилетия, исследователи определяют В.Ющенко как нарцисса, ребёнка, которого чрезмерно опекали.

\footnotetext{
${ }^{1}$ Dr Anna Chechelnitskaja, dr nauk historycznych, docent Państwowej Akademii Finansowej w Dniepropetrowsku, ul.Arżanowa 12, e-mail: angelichek05@list.ru
} 
Ю.Тимошенко, выросла без отца, ушедшего из семьи, с ненавистью к мужчинам, которых постоянно вытесняет из ближайшего окружения и т.д.

Автор определяет дальнейшие перспективы исследования, что позволяет увеличить качественный объём психоисторического дискурса.

Ключевые слова: психоистория, психоиторический дискурс, Б.Хмельницкий, И.Вишневецкий, столыпинская аграрная реформа, М.Грушевский, Великая отечественная война, Вторая мировая война, психоисторические портреты, В.Ющенко, Ю.Тимошенко, В.Янукович.

Формирование психоисторического дискурса украинской истории есть делом сложным и неблагодарным. Ведь дать описание всех исторических явлений и процессов под определённым углом зрения, так же с учётом их возникновения, не под силу одному исследователю. Ситуация усугубляется также тем, что психоистории присущ методологический индивидуализм, для преодоления которого необходима не только историческо-методологическая подготовка, но и психоаналитическая. Но как говорил известный персонаж из кинофильма «Полёт над гнездом кукушки»: «Я хотя бы попробовал». А посему подобная попытка имеет смысл, поскольку психоистория, выясняя мотивацию к исторической деятельности, решает целый ряд проблем, связанных с реализацией психогенеза в процессе исторического антропогенеза.

На данном этапе мы видим своё задание в том, чтобы попробовать систематизировать то, что наработано в плоскости психоисторического взгляда на украинскую историю, придать этим отдельным фрагментам логическую и хронологическую последовательность, оснастив дополнительными элементами дискурса. То бишь создать психоисторический прецендент, не носящий, естественно, абсолютный характер.

Изначальным, безусловно, следует считать вопрос периодизации украинской истории, схем которой существует предостаточно. Наиболее распространённой есть периодизация по этапам формирования украинской государственности: древняя история - до VI ст.; Средневековье - Киевская Русь, Галицко-Волынское княжество, Русско-Литовское княжество - VII-XV ст.; украинская казацкая держава XVI-XVIII ст.; украинские земли в составе Российской и Австро-Венгерской империй - ХІХ ст.; украинская революция - 1917-1921 рр.; Советская Украина 1921-1991; Украина в условиях независимости - 1991-по текущий момент ${ }^{2}$.

Психоисторическая периодизация, по Л.Демозу, складывается на основе психогенных стилей, которые основываются на общественном отношении к детству: от древнейших времён до IV ст.- стиль детоубийства; IV - XIV ст. стиль отказа; XIV-XVII - амбивалентный; XVIII - навязывающий; XIX-XX социализирующий.

Попробуем совместить эти две периодизации, а точнее, «нафаршировать» общепринятую периодизацию психоисторической начинкой.

Мы пока не касаемся самого древнего периода и начнём с истории Киевской Руси, которая составляет для нас сложность через времённую удалённость и

\footnotetext{
${ }^{2}$ Ресурс доступа: cheloveknauka.com
} 
перенасыщенность мифами разного характера. Поэтому выделим ту часть, которая может быть повергнута анализу, то есть традиционные характеристики данного периода:

1. Активность процессов, формирующих государство.

2. Формирование особенного статуса княжеской власти и законодательной базы.

3. Христианизация Руси.

В психоисторическом дискурсе эти течения общественно-политической жикни органично связаны, поскольку проистекают, в некотором смысле, из такой категории как телесность путём реализации коллективных фантазий. Л.Демоз с точки зрения общеметодологических принципов психоистории отмечает: «То, что обыкновенно называют «социальными институтами» - это исторические группыпредставители: церковь - это групповая фантазия зависимости, армия - групповая фантазия рождения, правительство - групповая фантазия заботы, капитализм групповая фантазия контроля, революция - групповая фантазия антизависимости, классовая система - групова фантазия уважения, школа - групова фантазия унижения» ${ }^{3}$.

При сопоставлении эволюции фантазий на Западе и периода существования Киевской Руси, последняя попадает под так называемый период «отказа», который имеет такие характеристики ${ }^{4}$ :

\begin{tabular}{|c|c|c|}
\hline $\begin{array}{l}\text { Уровень } \\
\text { фантазии }\end{array}$ & $\begin{array}{l}\text { Личностный } \\
\text { уровень }\end{array}$ & Исторический уровень \\
\hline Желаемого & $\begin{array}{l}\text { Отец/мать не } \\
\text { отказались от меня }\end{array}$ & $\begin{array}{l}\text { Феодальные связи, Великая Цепь Бытия, } \\
\text { культ Девы Марии, расцвет церкви, } \\
\text { мистическое слияние с Христом }\end{array}$ \\
\hline Защиты & $\begin{array}{l}\text { Я } \quad \text { отказался } \\
\text { отца/матери }\end{array}$ & $\begin{array}{ll}\text { Монастири, } & \text { крестовые } \\
\text { паломничество, уныние }\end{array}$ \\
\hline Бедствия & $\begin{array}{l}\text { Мать отказалась от } \\
\text { меня }\end{array}$ & $\begin{array}{l}\text { Экскоммуникация, безвластие, колдовство, } \\
\text { чертовщина }\end{array}$ \\
\hline
\end{tabular}

В соответствии с психогенной теорией истории психогенные стили определяют уровень развития личности в историческом контексте. Какого же типа личность является типичной для периода «отказа», которая является объектом нашего внимания:

\begin{tabular}{|c|c|c|}
\hline $\begin{array}{l}\text { Стиль } \\
\text { отказа }\end{array}$ & $\begin{array}{l}\text { Аутичная } \\
\text { личность }\end{array}$ & $\begin{array}{l}\text { Невключенная; нарциссическая; эксплуататорская, } \\
\text { паразитическая; недоверчивая; оральная агрессия; } \\
\text { мегаломания или слабость «я»; психопатичная; } \\
\text { нетерпимая к отсрочкам; отсутствие угрызений } \\
\text { совести; идеализация матери; без чувства времени }\end{array}$ \\
\hline
\end{tabular}

(Что касается последней характеристики, на неё обращают внимание даже публицисты образца Олеся Бузины, которые утверждают, что человек того времени воспринимал время циклически через смену сезонов, и только государство

\footnotetext{
3 Л. Демоз, Психоісторія.- Ростов-на-Дону: «Феникс», 2000, с. 182.

${ }^{4}$ Ibidem, c. 189.
} 
реализовало концепцию линейного времени из-за необходимости внедрения планирования ${ }^{5}$.

Российский исследователь А.Агафонов примерил метод психоистории в изучении такого феномена как донское казачество. Экстраполируем результаты его исследования по отношению к украинскому казачеству: казачество является отдельным психоклассом в украинском обществе того времени; психоистория украинского казачества может быть репрезентована как групповая фантазия, как результат исторической мотивации в протистоянии враждебным вторжениям; Запорожская Сечь стала синтезом индивидуальних устремлений, надежд, поведенческих мотиваций, желаний, которые приобрели форму коллективного решения, познавального процесса предметной направленности индивидов и общности в целом; характерной чертой психологии казачества является образность мышления и восприятия как формы познания.

Проблема политического лидерства в контексте истории казачества может рассматриваться через политическую деяльность Б.Хмельницкого и его оппонента И.Вишневецкого. В исследовании Г.Виноградова ${ }^{6}$, делается попытка создания гипотетических семиологических моделей поведенческих стратегий указанних политических деятелей., которые есть для нас значимими для определения мотиваций лидеров периода казачества:

- c точки зрения психологии того времени «все без исключения отношения на земле как Творении Божем считались точной проекцией Законов Божих, отступление от которых рассматривалось не просто как преступление, но и проявление сатанинского греха, искоренение которого было священной обязанностью христианина» ${ }^{7}$.

- данная характеристика присуща не только православным. Иеремия Вишневецкий, имеющий репутацию палача Украины, и со своей стороны реализовывает подобный сценарий, «ведь он стремился установить на подчинённых Речи Посполитой территориях законний порядок, в процессе которого, понятно, нередко склонялся к репрессиям по отношению к восставшим, но пытки были обычным явленим, а особенно в период официально объявленного военного положения» ${ }^{8}$. Оригинальним есть свидетельство того, что в своё время И.Вишневецкий дал клятву матери не изменять православию, как свидетельство его причастности к династии Рюриковичей и Гедиминовичей. Но всё равно принял католичество, осуществив парентификацю в виде католической церкви, что добавило ему благодаря авторитетности Ватикана как политических, внешних преференций, так и внутренних, личностных.

- И Хмельницкий, Вишневецкий имели так называемый комплекс архангела Михаила, который заключается в осуществлении особенной защитной функции легитимной власти.

\footnotetext{
${ }^{5}$ О. Бузина, Тайная история Украины-Руси. - Киев, 2012, с. 42.

${ }^{6}$ Г.М. Виноградов, Ярема Вишневецький vs. Богдан Хмельницький: дві семіологічні моделі поведінкових стратегій.//Наддніпрянська Україна: історичні процеси, події, постаті. - Зб. наукових праць. V випуск, 2007, с. 135-142.

${ }^{7}$ Ibidem, c. 136.

${ }^{8}$ Ibidem, c. 137.
} 
- С учётом психологии того времени Б.Хмельницкий имел определённые проблемы с приобретением государственных прав, поскольку по происхождению был мелким шляхтичем. И Б.Хмельницкий и другие украинские гетманы для законного осуществления собственных амбиций, направленных на процесс создания государства, должны были либо же получить княжеские титулы в соответствии с существующими процедурами, либо предложить другую альтернативную модель ${ }^{9}$. Осознание подобных нюансов позволяет нам понять нелогичные, на первый взгляд, «па» в поведении гетмана: постоянный поиск «высокой руки», молдавская «командировка» Т.Хмельницкого, поиск благословения Иерусалимского патриарха Паисия и т.д.

Следуя далее в соответствии с периодизацией, слегка коснёмся причин незавершённости столыпинской аграрной реформы. По мнению А.Ахтямова, эти причины лежат в плоскости взаимоотношений министров - П.Столыпина и C.Витте, а также в отношении к ним самого Николая II.

Какие же общие черты в личностных характеристиках министров отмечает Ахтямов В.В.:

Провинциализм, который стимулировал амбициозных Витте та Столыпина, двигаясь по служебной лестнице, тщательно изучать реальную жизнь.

- $\quad$ Общность образования - физико-математическое.

- Оба министра имели старших братьев, которые рано ушли из жизни. Существенное влияние на формирование личности каждого оказывали родные дядья. Оба были очень сентиментальными по отношению к жене и детям.

Яркой чертой была интуиция, которая позволяла отмечать людей схожего типа с очень высоким уровнем личной ответственности.

- Эволюционисты, противники вооружённых конфликтов, ярые монархисты.

Казалось бы, эти общности давали основу к пониманию и совместным действиям. Но история свидетельствует об обратном - о наличии конфликта между министрами реформаторами. Возможно, причина лежит в соционических различиях, которые обозначены исследователем. Во-первых, П.Столыпин интроверт с оригинальным мышлением, а С.Витте, в противовес ему, яркий, подвижный, конъюнктурный экстраверт. Ахтямов В.В. определяет корреляцию между личными качествами деятелей и их дальнейшей судьбой, а также влиянием на ход реформ. Характер Столыпина привёл его к жертве, даже к самопожертвованию, которое связано с отсутствием страха за собственную жизнь и авторитарностью. Витте не смог удержать власть, хотя его эмоциональность была эффективна при решении некоторых задач, без реализации которых он терял жизненную энергию. Во-вторых, то, что Ахтямов В.В. определяет как свойственную С.Ю.Витте истеричность, выплеснулась на все начинания П.А.Столыпина, а глубокая неприязнь С.Ю.Витте к П.А.Столыпину и холодная отчуждённость последнего чётко проявилась в их переписке и личных контактах ${ }^{10}$.

Выводы, сделанные Ахтямовим В.В., как раз есть примером того, что психоистория, не отрицая других методов познания исторической реальности,

\footnotetext{
${ }^{9}$ Ibidem, c. 139.

${ }^{10}$ Ресурс доступа: cheloveknauka.com
} 
раскрывает глубинные характеристики людей и событий. Использование таких, казалось бы, лишённых плотной телесности категорий «как раздражение Николая II на Столыпина», «стремление идти против большинства», «психологические противоположности - интровертность Столыпина и экстравертность Витте» иллюстрируют нам современное измерение такого явления как роль личности в истории.

Следующим фрагментом психоисторического дискурса украинской истории, который репрезентует проблему политического лидерства, есть период украинской национальной революции, знаковой фигурой которой является М.Грушевский. Уместно поставить вопрос: какие личностные характеристики политического деятеля, осознанные или нет, обеспечивают провал или успех поставленной задачи.

Монография В.Ващенко частично даёт ответ на вопрос: как неврастения М.Грушевского, или то, что он квалифицировал как её, повлияла на его политическое поведение, и, соответственно, на общеисторические события. Недаром в качестве одного из эпиграфов автор трансплантирует самохарактеристику М.Грушевского: «..я несчастливий и психопатичний» ${ }^{11}$. Исследуя родовые истоки возникновения неврастении, исследователь делает ударение на значимости отца в жизни М.Грушевского, смерть которого, например, заслонила факт женитьбы и рождения дочери ${ }^{12}$. Одновременно с этим неврастения трактуеться самим Грушевским как женская, материнская, составляющая его психики.

Для нас же самым значимым остаётся вопрос: как проецировалась неврастения М.Грушевского на процедуру строительства молодого украинского государства? Ответ: парадигмой патриарха. В.Ващенко констатирует, что в «Автобиографии» М.Грушевский прописывает собственную генеалогию в «мифических структурах Украины» ${ }^{13}$. То есть самоопределяет себя как значимую фигуру в украинской истории. История Украины - это история его семьи. Украина и мать историка проходят один и тот же обряд захоронения - «очищения огнем» (мать Грушевского была тяжело психически травмирована при пожаре в доме, из-за чего и умерла, не прийдя в себя). Это «очищение огнём» для Украины и есть разрыв со старым, а для историка - разрыв со старшим поколением. Если неврастения - это женщина-мать у М.Грушевского , наследство со стороны матери, материнская кров, вырождение, то не удивительно, что лекарство от неврастении, то есть огонь, будет лекарством от матери.

Таким образом, ситуация, которая имеет индивидуальное происхождение, определяемая исследователем путём транзактного анализа как неврастения вырождения, рассматривается как модель для всей нации.

Близкими к нам в исторической ретроспективе находятся Вторая мировая и Великая Отечественная войны, в следствие которых в современном украинском обществе существует такая психогруппа, а, возможно, и психокласс, «дети войны». В исследовании этих явлений мы должны избегать того, что, по определению

\footnotetext{
${ }^{11}$ В.В. Ващенко, Неврастенія: непрочитані історії. - Дніпропетровськ, ДНУ, 2002, с. 124.

${ }^{12}$ Ibidem, c. 127.

${ }^{13}$ Ibidem, c. 166
} 
К.Ясперса, есть «типичными оценками» ${ }^{14}$, которые опровергают наше экзистенциальное право на историческую боль як проявление самоуважения нации. Каким же образом психоистория раскрывает характер этих событий? Магистральное направление такого похода, на наш взгляд, можно обозначить благодаря тем выводам , которые сделали учасники «круглого стола», организованного международным изданием «Psychologies» (российская версия) $)^{15}$ :

1. Последствия военного опыта, если не были качественно психологически проработаны, проявляют себя в огрублении, в неспособности к усложнённым формам взаимодействия с другими людьми, в вытеснении болем объёмных представлений о мире. Нормой становится примитивное разделение на своих и чужих, практически племенное сознание: свои всегда правы, а чужие - всегда враги $^{16}$.

2. Поколение участников войны не способны из-за глубокой психотравму осуществить объективный исторический анализ. Их дети - второе поколение ощущают боль родителей, и для них обычные людские блага преобретают сверхценный характер, что искажает процесс познания и осмысления. Третье поколение уже удалено от травмирующих событий на больший промежуток времени, у негод остаточно психического ресурса, чтобы иметь дело со страшным опытом. Таким образом, на современных историков, внуков тех, кто воевал , возлагается эта миссия.

3. Опыт войны активно иллюстрируется личными историями, которые делают намёк в сторону феноменологического похода, метода в реконструкции и изучении событий войн сквозь призму не только общего, но и частного, личностного.

Таким образом, для преодоления идеологических мифов, современных стереотипов и некачественных установок в обществе и в науке, которые влияют на политические решения, качественно может повлиять психоистория. Ибо как отметил один из участников «круглого стола» социолог Л.Гудков: «...если мы не станем работать с прошлым, оно будет нас преследовать» ${ }^{17}$.

Продолжением обозначенного дискурса можна определить исследования на сугубо украинской почве, взятые на вооружение политологами и журналистами. Например, в виде деятельности Школы политической психологии, основные принципы исследований которой определены её руководителем Г.Балашовым:

А. В соответствии с методом психоистории исторические события рассматриваются с точки зрения личной психологи, когда личность формирует бытие, а не оборот. В конкретике это значит, что модель поведения, освоенная в детстве, человек в последствии воплощает в жизнь.

В. Материалом для анализа служат личные высказывания политиков, книги, которые они пишут. Официальные биографии не используются, поскольку имеют пиар-характер. Обязательно выясняються события, которые произошли в жизни будущих политиков в возрасте до 6 лет и любимая сказка.

\footnotetext{
${ }^{14}$ К. Ясперс, Смысл и назначение истории. - Москва: Изд-во политической литературы, 1991, c. 528 .

${ }^{15}$ Psychologies. - 2011, № 62. - C.56-65.

${ }^{16}$ Ibidem, c. 59.

${ }^{17}$ Ibidem, c. 60.
} 
С. Пребывая на високих властных должностях, украинские политики реализуют детскую систему родственных отношений. В зависимости от биографии они окружают себя символическими родителями, братьями и сёстрами. При этом роль т.наз. родственников могут играть как отдельные личности, так и целые государственные органы. Выяснение этих деталей позволяет прогнозировать, какую схему поведения выберет политик.

Благодаря исследованиям школы, В.Ющенко в соответствии с методологией Школы считается нарциссом, ребёнком которого чрезмерно опекали. В отношении политической линии бывшего президента, она ориентирована на личность отца, который был директором школы, а во время войны пребывал в Германии, навсегда оставшись под впечатлением от европейского благополучия: «Неудивительно, что тот вырос этаким директором сельской школы, мечтающим затащить земляков в ЕС. Даже помимо их воли - директор-то лучше знает» ${ }^{18}$.

В.Янукович из-за потери матери в детстве всю жизнь ощущал боль утраты, которую компенсировал постоянными материальными накоплениями. Ю.Тимошенко выросла мужененавистницей из-за ухода отца из семьи. А.Яценюк сейчас исполняет роль наследника - он представляет поколение, которое наследует политику Ющенко, его базовый страх - быть вторым.

Как мы видим в соответствии с общей периодизацией украинской истории, психоисторический дискурс в нашем исполнении носит крайне дискретный характер, причина которого указана вначале. Не заполнены полости целых периодов, например, до Киевской Руси (по Л.Демозу, период детоубийства), отсутствуют схемы психоисторических переходов от одной общественнополитической формации к другой, не разработан огромный психоисторический пласт XIX-XX ст.ст., не говоря уже о современности. Но пример тех историков, которые подобно Ж.Ле Гоффу, утверждали: «Я неизменно предпочитал человеческие существа абстракциям, но историк не в состоянии их понять иначе, чем в недрах исторических систем, в которых они жили»- постоянный стимул к поискам новых ракурсов национальной истории ${ }^{19}$.

\section{ЛИТЕРАТУРА}

[1] Psychologies. - 2011, № 62.

[2] Агафонов А.И. Донское казачество XVI - начала XX века: психологический портрет //Ресурс доступу: www.razdory-museum.ru/c_portrait.html

[3] Ахтямов В.В. Психоисторические аспекты жизни С.Ю.Витте и П.А.Столыпина//Автореферат соис.науч.ст.канд.ист.наук//www.dslib.net/istoria-otechestva/ahtjamov2.html/.

[4] Брехуненко В.А. Проблема причетності українських козаків до генези донського козацтва в історіографії // Ресурс доступа: http://cadetsfund.org.

[5] Бузина О. Тайная история Украины-Руси. - Киев, 2012.

[6] Ващенко В.В. Неврастенія: непрочитані історії. - Дніпропетровськ, ДНУ, 2002.

\footnotetext{
${ }^{18}$ Ресурс доступа: novaya.com.ua

${ }^{19}$ Ж. Ле Гофф., Цивилизация средневекового Запада. - Москва, 1992.
} 
[7] Виноградов Г.М. Ярема Вишневецький vs. Богдан Хмельницький: дві семіологічні моделі поведінкових стратегій.//Наддніпрянська Україна: історичні процеси, події, постаті. - Зб. наукових праць. V випуск, 2007.

[8] Демоз Л. Психоісторія.- Ростов-на-Дону: «Феникс», 2000.

[9] Ле Гофф Ж., Цивилизация средневекового Запада. - Москва, 1992.

[10]Ресурс доступа: cheloveknauka.com

[11]Ресурс доступа: novaya.com.ua

[12]Ясперс К. Смысл и назначение истории. - Москва: Изд-во политической литературы , 1991.

\section{DYSKURS PSYCHOHISTORYCZNY UKRAIŃSKIEJ HISTORII}

W danym artykule autor na podstawie znanego schematu periodyzacji historii Ukrainy wyodrębnia elementy dyskursu psychohistorycznego, proponując własną wersję ich zależności i spójności.

Psychohistoria jako metoda i niezależna dyscyplina naukowa istnieje od ponad czterdziestu lat, jednak w ukraińskiej historiografii nie znalazła odpowiedniej realizacji, mimo iż właśnie ona ilustruje nowoczesny format ludzkiego wymiaru historii.

Autorka analizuje dyskurs psychohistoryczny takich wydarzeń i okresów w ukraińskiej historii jak ukraińskie kozactwo oraz problem przywództwa hetmańskiego, reforma rolna Stołypina, ukraińska rewolucja narodowa przez pryzmat osobowości M. Hrushevskiego, Wielka Wojna Ojczyźniana i druga wojna światowa, psychohistoryczne portrety niektórych postaci politycznych współczesności.

Główne wnioski sformułowane przez autora: Kozacy są oddzielną psychoklasą we współczesnym im społeczeństwie ukraińskim; psychohistoria ukraińskiego kozactwa może być przedstawiana w postaci grupowej fantazji jako wynik historycznej motywacji sprzeciwu wrogim najazdom obcokrajowców; B.Chmelnicki miał pewne problemy z uzyskaniem prawa do przywództwa państwem, ponieważ z pochodzenia był tylko drobnym szlachcicem, on i inni ukraińscy hetmani do właściwego realizowania swoich ambicji w tworzeniu państwa musieli albo uzyskać tytuły książęce zgodnie $\mathrm{z}$ obowiązującymi procedurami, albo zaoferować inny model alternatywny.

Wskazano konflikt między władzą tradycyjną i reformatorami - S. Witte i P. Stołypinom, w którym główną rolę przejmuje imperator Mikołaj II. Stosunek cara do wymienionych ministrów charakteryzuje się stanem irytacji, blokującej racjonalne zrozumienie przez Mikołaja II konieczności fundamentalnych zmian w Imperium.

Co dotyczy okresu wojny, to doświadczenia wojenne, w przypadku gdy nie były psychologicznie opracowane, ujawniają się w zobojętnieniu, niezdolności do złożonych interakcji z innymi ludźmi, w wyparciu bardziej złożonych wyobrażeń o świecie.

Politycy ukraińscy, jak również inni, urzeczywistniają dziecięcy system relacji rodzinnych, czyli zgodnie z biografią otaczają siebie symbolicznymi rodzicami, braćmi i siostrami, tak w postaci ludzi jak i instytucji. Mówiąc o realnych politykach ostatniej dekady, naukowcy określili V.Juszczenkę jako narcyza, dziecka, którym nadmiernie opiekowali się. J.Tymoszenko, dorastała bez ojca, który opuścił rodzinę, w nienawiści do mężczyzn, których nieustannie wypycha z najbliższego otoczenia, itp.

Autor określa przyszłe perspektywy dla badań, przewidując zwiększenie objętości dyskursu psychohistorycznego o wysokiej jakości.

Słowa kluczowe: psychohistoria, dyskurs psychohistoryczny, B.Chmielnicki, I.Vyshnevetsky, reforma rolna Stołypina, M.Hrushevsky, Wielka Wojna Ojczyźniana, II wojna światowa, psychohistoryczne portrety, V.Juszczenko, J.Tymoszenko, V.Janukowycz. 


\section{PSYCHO-HISTORICAL DISCOURSE OF UKRAINIAN HISTORY}

In this article the author on the basis of well-known schemes of periodization of Ukrainian history highlights the elements of psychohistorical discourse, offering her version of their relationship and consistency.

Psychohistory as a method of self-discipline is already more than forty years old, but in Ukrainian historiography it hasn't obtained the high-quality implementation, even though it illustrates the format of a modern human dimension of history.

The author examines the psychohistorical discourse such events and periods in Ukrainian history as the Ukrainian Cossacks hetman and the problem of leadership, Stolypin's agrarian reform, the Ukrainian national revolution in the projection of personality M. Grushevsky, the Great Patriotic War and World War II, psychohistorical portraits of some political character of the modern period.

The main conclusions made by the author: the Cossacks is a separate psychoclass in contemporary Ukrainian society and psychohistory of Ukrainian Cossacks can be represented as group imagination as the result of a historical motivation as an opposition against hostile foreign invasion.

B.Khmelnitsky had some problems with obtaining the rights to the leadership of the state as originally he was only minor gentry, he and other Ukrainian hetmen had to either get princely titles in accordance with existing procedures, or to offer another alternative model if they wanted to put into practice their own ambitions in the process of creation of the state.

We have outlined a conflict between the traditional authorities and the reformers Sergei Witte and Pyotr Stolypin where the protagonist becomes Emperor Nicholas II.

The king's attitude to the named ministers can be described as irritation which prevents Nicholas II to understand rationally the need for radical changes in the empire.

One of the iconic figures of the Ukrainian national revolution is M.S.Grushevsky, as a neurotic person, he saw the way of healing himself with "fire", in which Ukraine had to be immersed.

The consequences of military experience, if not treated psychologically manifest the $\mathrm{He}$ also has a complex of the patriarch. With regards to the wars .

mselves in the coarsening, the inability to form complex interactions with other people in the displacement of more complex representations of the world

Ukrainian politicians, like any other carry out a child system of kindred .

That is, according to the biography, they surround themselves with symbolic parents, brothers and sisters, both as people and establishments .

Talking about the real politicians of the last decade, researchers have determined Yushchenko as narcissus, child who was taken care too much. Yulia Tymoshenko, as Little Red Riding Hood, grew up without a father, he left the famil, and so she hates men and constantly pushes them out of the nearest environment. The author outlines the future prospects of research, thus increasing the amount of high-quality psychohistorical discourse.

Keywords: Psychohistory, psychohistorical discourse, Ukrainian Cossacks hetman, Stolypin's agrarian reform, the Great Patriotic War and World War II, psychohistorical portraits, M. Grushevsky, Yushchenko, Yulia Tymoshenko

DOI:10.7862/rz.2014.hss.13

Przesłano do redakcji: czerwiec 2014

Przyjęto do druku: lipiec 2014 